\title{
Aligning Higher Education's Promise of Well-Being with Sustainability as a Purpose of Education
}

\author{
Katrin Kohl and Charles Hopkins
}

\section{Introduction}

In a world of increasing complexity, there is a growing demand for access to higher education. People of all ages aim at academic degrees to qualify for decent career opportunities in the future, often in hope of a better life. Numbers in higher education are globally on the rise with today approximately $38 \%$ gross enrolment in tertiary education (UNESCO 2018).

While there is an unspoken assumption that an academic degree opens up opportunities, in many countries still only a comparatively small number of students have access and the means to attend an institution of higher education. These inequalities are a major concern for education systems worldwide.

Therefore, for the first time in the history of United Nations (UN), the Sustainable Development Goal 4 (SDG target 4.3) explicitly requires equal access for women and men to an affordable tertiary education as an aspect of the international education agenda. Embedded as one of 169 targets in the 17 SDGs of the 2030 Agenda, access to higher education is an element in the vision of the world's future, aiming at an educated public and workforce.

Beyond educating bigger portions of future generations, higher education serves further roles in the 2030 Agenda. Better understanding and learning to cope with the world that we are in and that we have co-created, research and science are needed to serve society to find solutions for the grand challenges of today and tomorrow. Higher education is crucial for the individual and for societies in the pursuit of well-being and sustainable development.

\footnotetext{
K. Kohl $(\varangle) \cdot$ C. Hopkins

York University, Toronto, Canada

e-mail:kkohl@edu.yorku.ca

C. Hopkins

e-mail: chopkins@edu.yorku.ca 


\section{The Role of Higher Education: Teaching and Learning for Life}

It is widely understood that higher education can play a pivotal role to equip graduates with the knowledge and skills to seek career opportunities and create livelihoods; but also to learn making informed decisions in fast-changing environments and understanding potential consequences of individual and collective actions.

Graduates of higher education represent today's and most likely tomorrow's majority of leaders. They do not only shape their local and regional business world and government policies, but their lifestyle decisions most likely have consequences for others in our interconnected world. Graduates often become important societal influencers and therefore, the combined insight and skills gained in higher education programmes have an impact on economy, the environment and society.

Receiving higher education is not limited to achieving a degree based on knowing and applying technical expertise attained in the programme, but it means understanding that knowledge and skills taught are based on science. Students learn facts, but they also acquire the competency of how to research (new) knowledge for an entire lifetime. This skill is essential as science and technology continuously develop. What was taught during years of education will potentially be challenged. And every student entering higher education is welcome to contribute knowledge and seek better ways of doing things during their programme and beyond.

Higher education includes the opportunity to attain a broader personal skill set. Indepth factual examinations of topics combined with developing the ability to discuss differing opinions with peers are fundamental aspects of academic programmes. Through these interactions, students are expected to recognize a responsibility of respecting diverse worldviews, clarifying personal values and attaining leadership.

In addition, a growing number of students are expected to study abroad or to move between countries throughout the course of their professional career. And while the consequences of the COVID-19 world-changing pandemic are yet unknown, we are already expecting up to 1 billion climate migrants to move within their countries or across borders by 2050 , escaping the negative impacts of climate change. Consequently, many of today's students might not only be educated in several education systems but might contribute to other workforces and societies than of the countries where they received education. The ability to find ways to adapt and to lead a reasonable and meaningful life to be experienced in changing economic, social and environmental settings is crucial for today's students.

\section{The Role of Higher Education: Research}

Continuously working to expand factual knowledge, being critical of what we know and what we do with our knowledge and constantly seeking new ways to improve our understanding of our world is the focus of higher education research. More research 
is needed and to be shared to secure humankind's survival in an era of Anthropocene and a pandemic shaking our world. The 2030 Agenda aligns the need for education with such a need for research aspiring for a better future for all. We need research and science to fight hunger (SDG 2) and climate change (SDG 13), to conserve life below water (SDG 14), to create healthy societies (SDG 3) with sufficient industrial infrastructure (SDG 9), to benefit from clean energy (SDG 7), and decent employment opportunities (SDG 8). Fostering international partnership towards the global goals, facilitating responsible competition and providing research-based knowledge are at the core of higher education research (SDG 17).

\section{The Role of Higher Education: Service to Society}

In their third mission, higher education today attempts to serve society's development towards a better future. In particular, universities and colleges connect to and serve the local community through the knowledge created in the academic environment and through building relationships to businesses, but also to governments and the not-for-profit sector.

\section{Our Common Vision}

How do we envision a 'better future' or a 'better world'? A highly aspirational common vision since the 1980s and now for 2030 has been the quest for sustainable development. It drives the world's actions to eradicate poverty and create peaceful societies as a progress for humanity ".that meets the needs of today without compromising future generations? abilities to meet their needs. ..” (United Nations 1987).

Adopted as Agenda 21 by the UN in 1992 and in a belief of global partnership of all countries, the world started pursuing sustainable development as a fundamental principle to guide action. At that time, it was unanimously acknowledged that education would be a crucial instrument to achieve sustainable development for all. Chapter 36 Promoting Education, Public Awareness and Training of Agenda 21, prepared in advance to the 1992 Earth Summit in Rio de Janeiro, defined the elements of Education for Sustainable Development (further 'ESD') as (1) reorienting education towards sustainable development; (2) increasing public awareness; and (3) promoting training. The need for (4) access and retention in a quality education was the fourth element named in Chapter 36 and also stated in Agenda 21's Chapter 25 Children and Youth in Sustainable Development.

Since Agenda 21, many programmes and initiatives have recognized the concept and improved the emphasis on ESD internationally. The United Nations Educational, Scientific and Cultural Organization (UNESCO) was tasked to lead the implementation of Chapter 36 with approaches to reach students and educators at all levels of education and to create public awareness. 
A United Nations Decade on Education for Sustainable Development (20052014) was set to integrate principles, values and practices of sustainable development into all aspects of education and learning. A UNESCO Global Action Programme on Education for Sustainable Development (2015-2019) aimed to scale-up ESD and to accelerate progress. Now, a new ESD for 2030 Framework (2020-2030) focuses on ESD's specific function as a vital means of a quality education (SDG 4/SDG 4.7) and as a key enabler of all of the SDGs. These efforts have led to ESD becoming a relevant and much discussed education concept and to reach public interest, especially since the necessity to fight climate change has reached a new level of visibility through youth leadership.

Today, ESD's transformative potential to “... empower learners to transform themselves and the society they live in by developing knowledge, skills, attitudes, competences and values required for addressing global citizenship and local contextual challenges of the present and the future..." (UNESCO 2014) is often emphasized. It is important that the original four thrusts of ESD are infused in this definition to preserve ESD's holistic concept.

Closely connected to the discussions around sustainable development is the concept of well-being. Rooted in psychology, it was first discussed as a goal for national economies reaching beyond linear economic growth for their citizens, achieving prosperity, health and happiness within certain environments and economic circumstances. Being well is more than satisfying Maslowian needs and staying physically healthy. It includes finding meaningfulness and balance in one's life. Indigenous worldviews of well-being extend the concept beyond the well-being of humans to address the well-being of all life forms, present and future.

Goals of sustainable development and well-being often align but can also be opposites (e.g. if seeking well-being requires the use of natural resources or shortterm choices for individual well-being endanger long-term well-being for all). In this case, the pursuit of individual well-being must take into account the consequences for the collective well-being and be limited by global capacities.

\section{Achieving Well-Being Within Sustainable Development}

How does the higher education promise of individual well-being align with sustainable development becoming a purpose of education? How can universities and colleges actively shape the future while adapting and transforming themselves as institutions?

Firstly, students might initially work for individual goals of decent employment and hope to be 'well-off' through achieving a certain economic and social status in life than consciously aiming towards sustainable lifestyles. But, universities and colleges can question or broaden worldviews and offer exposure to new ways of thinking. Higher education does not only impart the factual knowledge but actively adds soft skills to equip students with competencies needed to achieve the common goal of sustainable development. Also, if the recognition of qualifications in higher 
education is brought forward as commenced by UNESCO, graduates will reach a new geographic level of opportunity allowing movement without losing credentials and creating new networks of international cooperation.

As a result, the opportunity to graduate for each student might come with an assumed moral price: the individual accepts their social responsibility and at times, takes on an overt or subtle leading position in collectively helping to reduce the imbalance in the world. Not everyone might become a leader, but everyone should have the competencies to make conscious choices within a value set of sustainability.

In addition, universities and colleges can actively reach out to those who might not see themselves in higher education and raise numbers and diversity of student cohorts throughout all academic disciplines, broadening the spectrum of attendees in their programmes and who will qualify for future leadership. In face of the COVID19 pandemic, higher education has just shown its unique potential to transform itself in previously unimaginable ways. In 2020, we have seen the unleashing of the digital potential of universities in moving to online and distance teaching overnight. A safe and healthy return to campus is preferred for human connections and is important for programmes where experiments and practice require physical attendance. Recruiting a sufficient number of students with adequate fee schedules to assure financial survival is needed. If full online and distance programmes are expanded, universities and colleges are no longer limited to recruiting students from their local community and regions and a small selection of students from abroad. These opportunities for globalized education efforts bring the goal of equal access for women and men to affordable tertiary education (SDG target 4.3) much closer to reality.

Secondly, higher education must bring forward more research for a sustainable future and underline the importance of science-based knowledge, the value of independent research and the need for international science collaboration. Broader involvement of enrolled students in research and research design might hold opportunities for diverse youth perspectives.

Undisputedly, the necessity of academic freedom with the freedom of teaching and discussion, freedom in carrying out research and disseminating and publishing the results and also the freedom to express opinions (UNESCO 1997) remains central. Yet, the recognition of the global objectives of international peace, understanding, cooperation and sustainable development as fundamental principles for exercising academic freedom is an imperative for research.

While striving towards sustainable development as the current vision of the world we want, higher education must retain its role as a strategic and trusted partner. The higher education community has been recognized as an important stakeholder and honest broker of knowledge and truth for coping with great challenges and the serious problem of sustainability.

Furthermore, higher education in all of its disciplines must question the concept of sustainable development as a continuing vision for the future. Sustainable development, as described in the 1980s and shaped but not fundamentally changed to date, has its limitations, such as being too vague at times, too human-centred and an idealistic, unattainable concept. What will be the world's next vision of a functional yet desirable future and what kind of education will be needed to make it reality? 
With the 2030 Agenda, higher education with all three streams of teaching, research and service to their community can play an important role. It is now time to create a strong unified voice on the global level to advocate for the commitment to a sustainable future for all. Under the impression of the urgency of the climate crisis and exponentially growing inequalities in the world, a broader approach to higher education's third mission in aligning the three streams of the mandate towards an overall service to society can create even more relevance for the higher education community as a whole.

If graduates also commit to serving society during their careers and with personal choices, they can influence trends and public opinion. Conducting research to gather and share new knowledge and to develop innovation processes can help societies striving towards peace and sustainable development.

In working for global goals, international partnerships are crucial. They help to understand the various perspectives infused by knowledge, history and culture. They serve as learning circles, for peer-to-peer exchange and to generate new joint and collaborative ideas and ventures. The IAU Global Cluster on Higher Education and Research for Sustainable Development is one of the most relevant global initiatives to target the SDGs in higher education and contributing perspectives to the global discussion. IAU, associated with UNESCO, assists the higher education community to enhance their policies, develop appropriate responses and support institutions to achieve their goal set within the SDGs. The IAU Cluster encourages a holistic approach to the SDGs, focusing specifically on the various and multi-faceted aspects of universities in a whole-institution approach. While sustainable development itself or its succeeding vision are broader than the SDGs, the latter offers a current and accepted global framework to develop strategies in higher education institutions towards a sustainable future.

As SDG 4 is both a singular goal as well as interrelated with the other SDGs, it is of utmost importance to ensure its successful implementation. The IAU SDG 4 Subcluster particularly encourages universities and colleges to localize SDG-inspired action at the institutional level to improve social impact and expound upon social responsibility. It also aims at a better understanding of the potential of addressing the SDGs as a driver of transformation and promotes ESD as an element of a quality education in light of SDG 4.

ESD, embedded throughout all aspects of higher education, is the key to unlock the potential with providing educated future leaders, providing the science-based knowledge needed and localizing issues within the SDGs to identify and improve the particular sustainability issues in the community. If ESD is given priority and the means for further development and implementation, higher education alone and in partnerships within the community and beyond can significantly contribute to the well-being of all and greatly enhance the chances for a more sustainable future. 


\section{References}

UNESCO (1997). Recommendation concerning the Status of Higher-Education Teaching Personnel. Retrieved from: http://portal.unesco.org/en/ev.php-URL\$_\$ID=13144\&URL\$_\$DO=DO\$_ \$TOPIC\&URL\$_\$SECTION=201.html (16.05.2020)

UNESCO (2014). UNESCO World Conference on Education for Sustainable Development, AichiNagoya, Japan, 2014: Aichi-Nagoya Declaration on Education for Sustainable Development. Retrieved from: https://unesdoc.unesco.org/ark:/48223/pf0000231074. (16.05.2020)

UNESCO Institute for Statistics (2018). Sustainable Development Goal 4: 4.3.2 Gross enrolment ratio for tertiary education by sex (administrative data). Retrieved from: http://data.uis.unesco. org/ (16.05.2020)

United Nations (1987). United Nations General Assembly: Development and International Co-operation: Environment Report of the World Commission on Environment and Development. Annex. Report of the World Commission on Environment and Development. Our Common Future. Released by the Brundtland Commission. Retrieved from: https:// sustainabledevelopment.un.org/content/documents/5987our-common-future.pdf. (16.05.2020)

United Nations (1992). United Nations Conference on Environment and Development. Earth summit, Agenda 21. Retrieved from: http://www.un-documents.net/agenda21.htm (16.05.2020)

Katrin Kohl is Focal Point for SDG 4 (Quality Education) at the Higher Education and Research for Sustainable Development (HESD) Global Cluster, International Association of Universities (IAU). She is Executive Coordinator to the UNESCO Chair, York University (Canada), and responsible for overall strategy and global research. With a background in law and management, she served as Managing Director of the German Commission for UNESCO and as Strategic Advisor to the Vice-Chancellor at the University of Düsseldorf (Germany) in prior positions.

Charles Hopkins holds the UNESCO Chair in Reorienting Education towards Sustainability at York University (Canada) serving the Global Education 2030 Agenda with research and in coordinating two global networks: the International Network of Teacher Education Institutions (INTEI) and the \#IndigenousESD research network focusing on the education of Indigenous youth. Hopkins is also Advisor to the Global Network of Regional Centres of Expertise on ESD, and CoDirector of the Asia-Pacific Institute on ESD in Beijing (China).

Open Access This chapter is licensed under the terms of the Creative Commons Attribution 4.0 International License (http://creativecommons.org/licenses/by/4.0/), which permits use, sharing, adaptation, distribution and reproduction in any medium or format, as long as you give appropriate credit to the original author(s) and the source, provide a link to the Creative Commons license and indicate if changes were made.

The images or other third party material in this chapter are included in the chapter's Creative Commons license, unless indicated otherwise in a credit line to the material. If material is not included in the chapter's Creative Commons license and your intended use is not permitted by statutory regulation or exceeds the permitted use, you will need to obtain permission directly from the copyright holder.

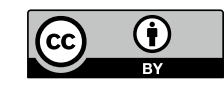

